\title{
Penerapan Zero Runoff System (ZROS) dan Efektivitas Penurunan Limpasan Permukaan pada Lahan Miring di DAS Cidanau, Banten
}

\author{
"Yanuar Chandra Wirasembada, Budi Indra Setiawan, Satyanto Krido Saptomo \\ Departemen Teknik Sipil dan Lingkungan, Fakultas Teknologi Pertanian, Institut Pertanian Bogor \\ ${ }^{*}$ yanuarchandraw @apps.ipb.ac.id
}

Received: 15 September 2017 Revised: 25 Oktober 2017 Accepted: 3 November 2017

\begin{abstract}
Runoff is one of flood and erosion causal factor in Indonesia. Runoff occurred when rainfall cannot be infiltrated and flowed on the ground surface. Cidanau watershed has quite high rainfall average (2573 mm/year) so it has high runoff potential. Zero Runoff System (ZROS) is one of water conservation way which can infiltrate runoff to the ground using permeation structures. ZROS's successful parameter in order to decreasing runoff rate can be observed by the soil water content differences before and after ZROS application. Soil water content estimation was conducted by water balance model with and without runoff and then it is compared with soil water content from measuring. The simulation results indicated that soil water content in the research field before and after ZROS application is 0.476 and $0.569 \mathrm{~m}^{3} / \mathrm{m}^{3}$ respectively. The simulation is also conducted for past 10 years (2004-2013) and resulted higher soil water content if ZROS were applied. This results indicates that ZROS capable to decrease and permeate runoff to the ground and then increase soil water content level. Water balance model with and without runoff has coefficient of determination $\left(R^{2}\right)$ 0.606. It means that this model could simulate the soil water content differences before and after ZROS application valid relatively.
\end{abstract}

Keywords: Permeation structure, runoff, soil water content, water balance model, zero runoff system

\begin{abstract}
Abstrak
Limpasan permukaan (runoff) merupakan salah satu penyebab terjadinya banjir dan erosi di Indonesia. Salah satu Daerah Aliran Sungai (DAS) yang mempunyai peran penting di Provinsi Banten adalah DAS Cidanau. DAS Cidanau memiliki curah hujan tahunan rata-rata cukup tinggi (2573 mm/tahun) sehingga memiliki potensi runoff yang tinggi. Zero Runoff System (ZROS) merupakan upaya konservasi air dengan cara meresapkan runoff ke dalam tanah menggunakan bangunan peresapan. Parameter keberhasilan ZROS dalam mengurangi runoff berupa perbedaan kadar air tanah sebelum dan sesudah penerapan ZROS. Estimasi kadar air tanah dilakukan menggunakan model kesetimbangan air dengan dan tanpa runoff kemudian dibandingkan dengan data kadar air tanah hasil pengukuran. Penelitian ini dilakukan pada bulan November 2013 sampai dengan Mei 2014. Pada penelitian ini, lahan yang digunakan berupa kebun seluas $8472 \mathrm{~m}^{2}$. Rorak dibangun sebanyak 12 buah dan diletakkan di sepanjang jalur limpasan permukaan. Hasil simulasi kadar air tanah di lokasi penelitian sebelum dan sesudah penerapan ZROS berturut-turut sebesar 0,476 dan 0,569 $\mathrm{m}^{3} / \mathrm{m}^{3}$. Simulasi juga dilakukan selama 10 tahun terakhir (2004-2013) dan menghasilkan kadar air tanah yang lebih tinggi apabila ZROS diterapkan. Hasil tersebut mengindikasikan bahwa ZROS mampu mengurangi dan meresapkan runoff ke dalam tanah sehingga menaikkan kadar air tanah. Model kesetimbangan air dengan dan tanpa runoff ini mempunyai nilai tingkat kepercayaan $\left(R^{2}\right)$ yang cukup tinggi, yaitu sebesar ,.606 sehingga kinerja simulasi relatif valid dalam mensimulasikan perubahan kadar air tanah sebelum dan sesudah diterapkan ZROS.
\end{abstract}

Kata kunci: Bangunan peresapan, kadar air tanah, model kesetimbangan air, runoff, zero runoff system 


\section{Pendahuluan}

Limpasan permukaan (runoff) merupakan sebagian dari air hujan yang mengalir di atas permukaan tanah menuju sungai, danau atau laut. Runoff terjadi apabila tanah tidak mampu lagi menginfiltrasikan air di permukaan tanah karena tanah sudah dalam keadaan jenuh. Runoff juga dapat terjadi apabila hujan jatuh di permukaan yang bersifat impermeable seperti beton, aspal, keramik, dan lain-lain. Peristiwa banjir dan erosi yang sering melanda beberapa wilayah di Indonesia merupakan dampak dari runoff yang tidak dapat ditangani dengan baik.

Indonesia sebagai negara beriklim tropis mempunyai curah hujan yang tinggi. Salah satu daerah yang mempunyai curah hujan tinggi adalah Daerah Aliran Sungai (DAS) Cidanau. DAS Cidanau terletak membentang dari Kabupaten Pandeglang sampai Kabupaten Serang, Provinsi Banten. Rata-rata curah hujan di DAS Cidanau selama 10 tahun terakhir (2004-2013) sebesar 2573 $\mathrm{mm} /$ tahun. Hal tersebut berdampak positif berupa ketersediaan air yang sangat melimpah. Namun, curah hujan yang tinggi juga memiliki dampak negatif berupa tingginya aliran permukaan.

Secara tidak langsung, runoff juga mempunyai pengaruh terhadap kualitas air sungai. Daerah yang memiliki runoff yang tinggi umumnya mempunyai kualitas air sungai yang buruk. Parameter kualitas air yang berpengaruh terhadap besarnya runoff adalah kekeruhan atau turbiditas. Runoff merupakan salah satu penyebab utama sungaisungai di Indonesia mempunyai tingkat kekeruhan yang tinggi, termasuk Sungai Cidanau. Data PT. Krakatau Tirta Industri tahun 2012 menunjukkan bahwa tingkat kekeruhan Sungai Cidanau berada pada level 500 NTU. Apabila tidak ada tindakan pencegahan, tingkat kekeruhan akan terus meningkat dan melebihi baku mutu yang ditetapkan pemerintah, yaitu 600 NTU.

Sungai Cidanau juga mempunyai peran yang sangat vital bagi ketersediaan air di hilir DAS. Wilayah hilir DAS Cidanau berupa pemukiman dan kawasan industri di Kota Cilegon serta sebagian wilayah Kabupaten Serang. Oleh karena itu, diperlukan tindakan pencegahan untuk mencegah kemungkinan terjadi kerusakan lahan dan pencemaran Sungai Cidanau yang lebih parah.

Berdasarkan permasalahan yang terjadi di DAS Cidanau, maka dilakukan penelitian untuk menekan laju runoff yang tinggi dengan menerapkan konsep zero runoff system (ZROS). Konsep ini menganalisis dan mendesain bangunan hidrolika yang mudah, murah dan ramah lingkungan untuk mengurangi limpasan permukaan dan mengkonversinya menjadi cadangan air tanah. Implikasi dari reduksi runoff ini yaitu penurunan laju erosi dan peningkatan cadangan air tanah untuk berbagai keperluan, khususnya di bidang pertanian. Masalah yang akan dikaji dalam penelitian ini adalah: apakah dengan diterapkannya zero runoff system (ZROS) dapat menurunkan limpasan permukaan secara signifikan dan sejauh mana ZROS dapat meningkatkan cadangan air tanah di lokasi kajian. Sedangkan penelitian ini bertujuan untuk menduga besaran runoff yang terjadi di lokasi penelitian, mengevaluasi efektifitas konsep ZROS, dan mengidentifikasi dan validasi hubungan curah hujan dengan cadangan air tanah di lokasi penelitian menggunakan Zorro Model.

\section{Pendugaan limpasan permukaan di lapangan}

Penentuan besar aliran permukaan di lokasi penelitian menggunakan metode Soil Conservation Service Curve Number (SCS-CN). Metode ini dikembangkan oleh United States Department of Agriculture (USDA) pada tahun 1973 dan masih terus dikembangkan hingga saat ini. Metode ini sudah digunakan oleh beberapa peneliti (Steenhuis et al., 1995; Reshma et al., 2010; Tejaswini et al., 2011; Luxon \& Pius 2013) tidak hanya di Amerika Serikat tetapi juga di negara lain karena memberikan hasil yang valid dan konsisten (Kumar \& Rishi 2013).

Pada metode SCS, RO dianggap 0 apabila curah hujan $(\mathrm{P}) \geq 0,2 \mathrm{~S}$. Variabel $\mathrm{S}$ adalah perbedaan kondisi tanah dan tutupan lahan terhadap nilai curve number $(\mathrm{CN})$. Jika curah hujan $>20 \%$ dari $\mathrm{S}$, RO dihitung menggunakan persamaan 1 dan Persamaan 2 (USDA 1986).

$$
\begin{aligned}
& S=\left(\frac{1000}{C N}-10\right) \times 25,4 \\
& R O=\frac{(P-0.2 S)^{2}}{P+0,8 S}
\end{aligned}
$$

Dimana $\mathrm{RO}=$ aliran permukaan $(\mathrm{mm}), \mathrm{P}=$ curah hujan $(\mathrm{mm}), \mathrm{S}=$ kondisi tanah tutupan lahan terhadap $\mathrm{CN}$ dan $\mathrm{CN}=$ curve number.

Angka CN merupakan angka yang menggambarkan potensi terjadinya runoff pada beberapa jenis tutupan lahan tertentu. Nilai CN bervariasi dari 0 sampai 100. Untuk kondisi hidrologi tanah, USDA (1986) mengelompokkan beberapa tekstur tanah ke dalam empat jenis kondisi hidrologi tanah berdasarkan laju infiltrasi minimum. 


\section{Sistem penampungan dan peresapan air hujan}

Konservasi air bertitik pusat pada pemanfaatan air hujan seefisien mungkin sehingga tidak terjadi banjir pada musim hujan dan terdapat cukup air pada musim kemarau. Pemanfaatan air hujan ini erat kaitannya dengan produksi lahan pertanian, terutama pada musim kemarau. Air hujan yang ditampung dan diresapkan ke dalam tanah akan menambah kelembapan tanah sehingga dapat meningkatkan cadangan air tanah untuk tanaman.

Penelitian ini berupaya melakukan konservasi air dengan cara meningkatkan cadangan air pada zona perakaran tanaman melalui pengendalian aliran permukaan (runoff) dengan cara pemanenan hujan (rainfall harvesting) menggunakan bangunan resapan berupa rorak dan saluran pengumpul. Upaya ini merupakan cara yang paling mudah untuk mengkonservasi air. Beberapa penelitian yang sudah dilakukan di beberapa negara (Oni et al., 2008 ; Kumar et al., 2011; Afolayan et al., 2012; Otti \& Ezenwaji 2013; Yeasmin \& Rahman, 2013) menyebutkan bahwa konservasi air memanfaatkan air hujan sangat efektif dan efisien baik di musim hujan maupun di musim kemarau.

Rorak adalah tempat untuk menampung dan meresapkan air yang dibuat di bidang olah atau di saluran peresapan untuk memperbesar resapan air ke dalam tanah dan menampung tanah tererosi (Surdianto, 2012). Faktor terpenting apabila ingin membuat rorak yaitu air hanya boleh tergenang beberapa saat. Umumnya, rorak berukuran panjang 50-100 cm, lebar 25-50 cm dan kedalaman 25-50 $\mathrm{cm}$. Rorak dapat disesuaikan dengan kondisi lahan dan curah hujan setempat.

Pada penelitian ini, dimensi rorak disesuaikan dengan potensi aliran permukaan di lapangan. Aliran permukaan di lokasi penelitian dihitung dengan menggunakan Metode Rasional, lihat Persamaan 3 dan Persamaan 4 (Chow et al., 1988).

$$
\begin{aligned}
& I=\frac{R_{24}}{24}\left(\frac{24}{t}\right)^{\frac{2}{3}} \\
& Q=0.278 . C . I . A
\end{aligned}
$$

Dimana $\mathrm{Q}=$ debit aliran permukaan $\left(\mathrm{m}^{3} / \mathrm{dtk}\right), \mathrm{A}=$ luas daerah tangkapan hujan $\left(\mathrm{km}^{2}\right), \mathrm{C}=$ koefisien limpasan, $\mathrm{I}=$ intensitas curah hujan rata-rata ( $\mathrm{mm} / \mathrm{jam}), \mathrm{t}=$ durasi curah hujan (jam), $\mathrm{R}_{24}=$ curah hujan rencana $(\mathrm{mm})$

\section{Konsep kesetimbangan air}

Proses kesetimbangan air di dalam zona perakaran tanaman ditunjukkan pada Gambar 1. Irigasi (I) dan curah hujan $(P)$ merupakan air yang masuk ke dalam zona perakaran. Sebagian $(I)$ dan $(P)$ tersebut akan hilang melalui aliran permukaan $(Q r)$ dan perkolasi $(D P)$ yang secara bertahap akan mengisi muka air tanah. Sebagian air tersebut juga akan bergerak ke atas karena gaya kapiler $(G W)$. Evaporasi yang terjadi di permukaan tanah dan tanaman akan mengurangi air di zona perakaran. Kesetimbangan air tanah pada zona perakaran oleh Pereira dan Allen (1999) dinyatakan dalam Persamaan 5.

$$
\theta_{i}=\theta_{i-1}+\frac{\left\lfloor\left(P_{i}-Q_{r, i}\right)+I_{n, i}-E T c_{i}-D P_{i}+G W_{i}\right\rfloor}{1000 Z r_{i}}
$$

Dimana $\theta_{i}=$ kadar air tanah volumetrik di zona perakaran pada hari ke-i $\left(\mathrm{m}^{3} / \mathrm{m}^{3}\right), \theta_{i-1}=$ kadar air tanah volumetrik pada hari sebelumnya $\left(\mathrm{m}^{3} / \mathrm{m}^{3}\right), P_{i}$ $=$ curah hujan pada hari ke-i $(\mathrm{mm}), Q_{r . i}=$ runoff pada hari ke-i $(\mathrm{mm}), I_{n, i}=$ kedalaman irigasi pada hari ke-i $(\mathrm{mm}), E T c_{i}=$ evapotranspirasi tanaman pada hari ke-i $(\mathrm{mm}), D P_{i}=$ perkolasi ke bawah zona perakaran pada hari ke-i $(\mathrm{mm}), G W_{i}=$ kontribusi pergerakan kapiler dari air bawah tanah pada hari ke-i $(\mathrm{mm}), Z r_{i}=$ kedalaman zona perakaran (m).

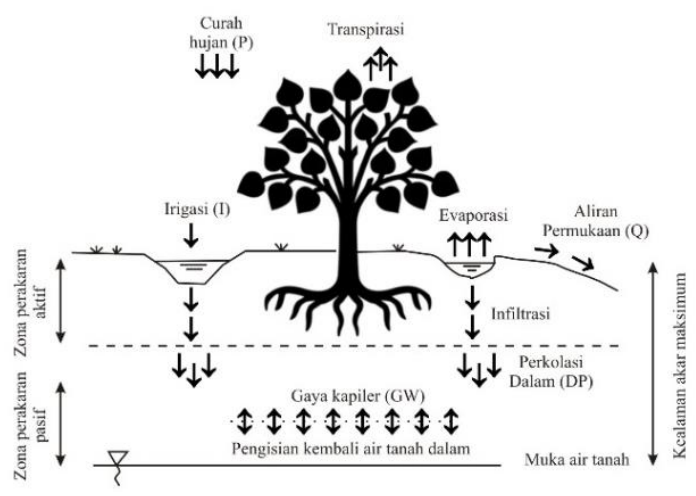

\section{Gambar 1. Skema konsep kesetimbangan air tanah di lapangan}

Persamaan 5 menunjukkan bahwa aliran permukaan $(Q r)$ berpengaruh langsung terhadap ketersediaan air di dalam tanah. Aliran permukaan juga menjadi parameter yang paling dominan dalam pengaruhnya terhadap kesetimbangan air. Oleh karena itu, untuk mempertahankan agar kadar air tanah di sekitar perakaran selalu berada pada kisaran yang tersedia bagi tanaman, perlu upaya untuk mengurangi $Q r$.

Upaya yang dapat dilakukan untuk mengurangi $Q r$ yaitu dengan membuat lubang resapan atau rorak yang disertai saluran pengumpul untuk menghilangkan runoff. Tidak ada irigasi yang dilakukan di lahan perkebunan ini. Apabila rorak tersebut diasumsikan mampu menahan runoff secara keseluruhan, maka nilai $Q r$ dan $G W$ 
menjadi tidak ada (nol) sehingga Persamaan 6 menjadi:

$$
\theta_{i}=\theta_{i-1}+\frac{\left[P_{i}-E T c_{i}-D P_{i}\right]}{1000 Z r_{i}}
$$

\section{Penentuan kadar air tanah di lapangan}

Kadar air tanah diperlukan untuk mengetahui tingkat keberhasilan sistem penampungan dan peresapan aliran permukaan. Data kadar air tanah di lapangan diperlukan untuk validasi antara hasil simulasi dengan hasil pengukuran di lapangan. Oleh karena itu, penentuan kadar air tanah di lapangan secara cepat, tepat dan akurat sangat diperlukan sebagai syarat keabsahan hasil simulasi.

Untuk mendapatkan nilai kadar air tanah secara cepat, tepat, akurat dan mudah, digunakan metode pengukuran tidak langsung dengan memanfaatkan sifat-sifat dielektrik tanah seperti konduktivitas, kapasitansi dan impedansi listrik pada suatu media berpori. Salah satu caranya yaitu menggunakan tensiometer keramik. Tensiometer keramik pertama kali digunakan untuk mengukur kadar air tanah pada tahun 1932 oleh Gardner (Bowo et al., 2009). Seiring berjalannya waktu, prinsip pengukuran kadar air tanah memanfaatkan sifat dielektrik terus berkembang. Salah satunya adalah penggunaan sensor kadar air tanah.

Pada penelitian ini, pengukuran kadar air tanah di lapangan menggunakan metode tidak langsung. Metode ini menggunakan sensor dan data logger untuk menyimpan hasil pengukuran sensor. Sensor yang digunakan yaitu sensor kelembapan tanah dengan nomor seri 5TE dan EC-5 dari Decagon. Untuk data logger, jenis yang digunakan yaitu Em50 (Gambar 2).

\section{Bangunan resapan}

Sistem bangunan resapan dibuat di sekitar titik terjadinya limpasan permukaan. Lahan yang diterapkan ZROS berupa perkebunan dengan kemiringan lahan sebesar $7,5^{\circ}$ atau $13 \%$. Pada kasus ini, runoff terjadi dan terpusat pada jalan setapak sehingga pembuatan rorak difokuskan di dekat jalan setapak tersebut. Tujuan dibuat rorak yaitu menghilangkan runoff di jalan setapak tersebut dan meresapkan runoff ke dalam tanah. Sebelum dibuat rorak, pemetaan lahan harus dilakukan terlebih dahulu agar diketahui kontur lapangan sehingga arah aliran air dapat diketahui.

Pada zero runoff system, dimensi dan jumlah rorak ditentukan berdasarkan potensi runoff yang terjadi di lapangan. Semakin besar potensi runoff yang terjadi, semakin banyak jumlah rorak yang dibutuhkan atau semakin besar dimensi rorak tersebut. Penetapan jumlah dan dimensi rorak menggunakan simulasi pada Microsoft Excel yang dilengkapi dengan Visual Basic Application.
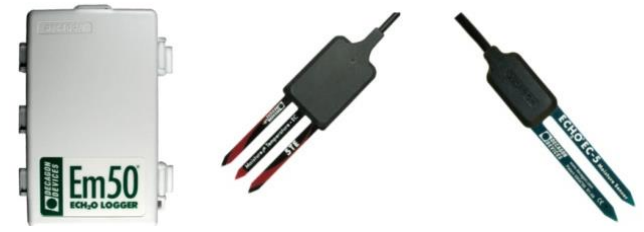

\section{Gambar 2. Jenis instrumen yang digunakan pada penelitian ini (dari kiri ke kanan: Em50, 5TE, dan EC-5)}

\section{Kalibrasi sensor kadar air tanah}

Kadar air tanah yang diukur oleh sensor 5TE maupun EC-5 keluarannya sudah dalam bentuk kadar air volumetrik $\left(\mathrm{cm}^{3} / \mathrm{cm}^{3}\right)$. Namun, angka tersebut dianggap masih belum representatif dengan data kadar air tanah aktual di lapangan. Oleh karena itu, diperlukan kalibrasi sensor agar hasil pengukuran sensor sama dengan kadar air aktual di lapangan.

Kalibrasi sensor dilakukan dengan cara mengambil sampel tanah dari lokasi penelitian kemudian dikeringkan dengan cara dijemur di bawah terik matahari. Tanah yang sudah kering kemudian dimasukkan ke dalam wadah berukuran 3-5 liter lalu diukur menggunakan kedua sensor. Tanah tersebut kemudian dimasukkan ke dalam ring sample untuk selanjutnya diukur kadar airnya dengan menggunakan metode gravimetri. Perlakuan tersebut dilakukan berulang-ulang dengan masing-masing perlakuan ditambahkan $200 \mathrm{ml}$ air. Hasil kadar air tanah dari pengukuran sensor dan pengukuran gravimetri kemudian diplot ke dalam grafik sehingga diperoleh persamaan kalibrasi menggunakan regresi linear.

\section{Metode}

Penelitian dilakukan di lahan perkebunan warga di Desa Ciomas, Kabupaten Serang, Provinsi Banten dengan luas $8.472 \mathrm{~m}^{2}$. Penelitian ini dilaksanakan dari bulan November 2013 - Mei 2014. Untuk analisis data berupa model kesetimbangan air dengan dan tanpa zero runoff system (ZROS) dilakukan menggunakan perangkat lunak Microsoft Excel 2007 yang dilengkapi dengan Visual Basic Application. Simulasi dilakukan secara harian dari tahun 2004 sampai dengan 2013 dan simulasi selama periode penelitian (1 November 2013 sampai 31 Mei 2014). Validasi model dilakukan dengan cara membandingkan kadar air tanah hasil pengukuran dengan hasil simulasi. Secara umum, prosedur simulasi ZROS disajikan pada Gambar 3. 


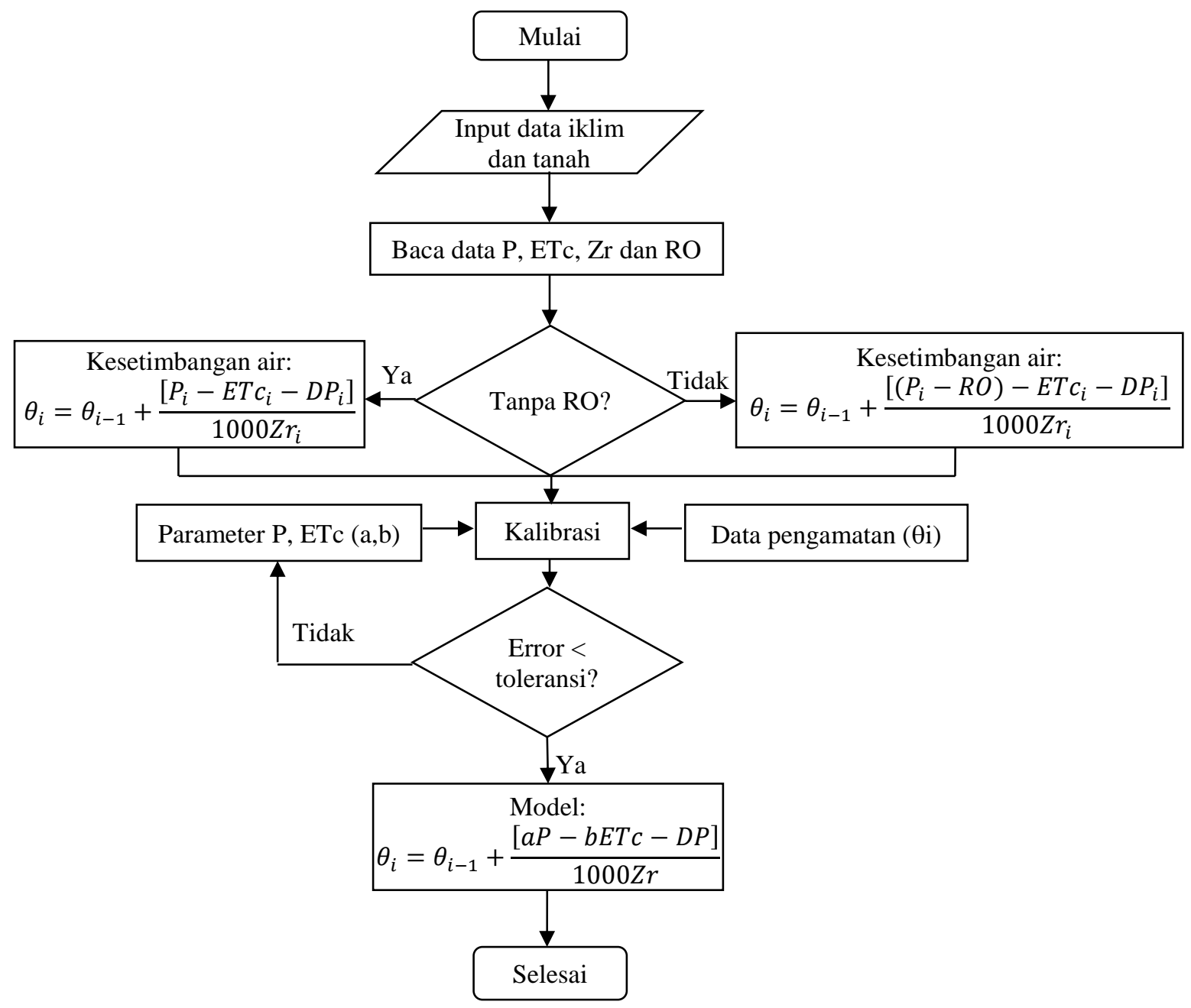

Gambar 3. Diagram alir model analisis kesetimbangan air dengan dan tanpa aliran permukaan

Data yang dikumpulkan dalam penelitian ini meliputi data sekunder dan data primer. Data sekunder diperoleh secara tidak langsung berupa catatan maupun hasil penelitian dari pihak lain. Data sekunder yang digunakan pada penelitian ini yaitu data iklim berupa data curah hujan harian dan data temperatur selama 10 tahun terakhir (20042013).

Data primer diperoleh secara langsung melalui pengamatan dan pengukuran langsung di lapangan. Data primer yang digunakan adalah data curah hujan selama penelitian, sifat fisik tanah, laju infiltrasi lahan dan kadar air tanah. Data curah hujan harian selama penelitian diperoleh dengan menggunakan alat penakar curah hujan manual.

Data fisik tanah diperoleh dari analisis laboratorium dari beberapa sampel tanah dengan kedalaman 0-75 cm. Laju infiltasi lahan diperoleh menggunakan mini disk infiltrometer. Alat ini mampu mengukur laju infiltrasi secara on-site sehingga tidak perlu mengukur infiltrasi di laboratorium. Untuk data kadar air tanah, diperoleh dari pembacaan sensor EC-5 dan 5TE yang dipasang pada kedalaman 0-25 $\mathrm{cm}$ dari permukaan tanah.

Data curah hujan merupakan data curah hujan harian yang terukur dalam penakar curah hujan manual, sedangkan evapotranspirasi merupakan hasil perhitungan. Agar analisis hasil simulasi mendekati kondisi ideal dengan data hasil pengukuran di lapangan maka ditambahkan faktor koreksi untuk parameter hujan $a$ dan evapotranspirasi $b$ maka Persamaan 7 menjadi:

$\theta_{i}=\theta_{i-1}+\frac{\left[a P_{i}-b E T c_{i}-D P_{i}\right]}{1000 Z r_{i}}$

Faktor koreksi hujan $a$ dan evapotranspirasi $b$ diperoleh dengan membandingkan data hasil simulasi dengan data observasi pada waktu yang sama. Minimalisasi terhadap deviasi dari model (error) dilakukan dengan menggunakan solver pada Microsoft Excel 2007. 


\section{Hasil dan Pembahasan}

\section{Estimasi runoff}

Curah hujan yang jatuh di lokasi penelitian tidak seluruhnya dapat terinfiltrasi ke dalam tanah. Sebagian dari curah hujan tersebut mengalir di permukaan tanah dalam bentuk runoff. Hasil dari perhitungan limpasan permukaan disajikan dalam bentuk grafik pada Gambar 4 .

Gambar 4 menunjukkan bahwa runoff yang terjadi berkisar antara 700-1500 mm/tahun. Angka tersebut cukup besar sehingga perlu penangangan agar runoff tersebut dapat ditekan. Rata-rata, $35.26 \%$ dari curah hujan per tahun di lapangan tidak dapat dimanfaatkan dan menjadi runoff. Angka tersebut apabila ditekan dan diresapkan ke dalam tanah, maka manfaat yang diperoleh akan sangat bermanfaat bagi masyarakat sekitar.

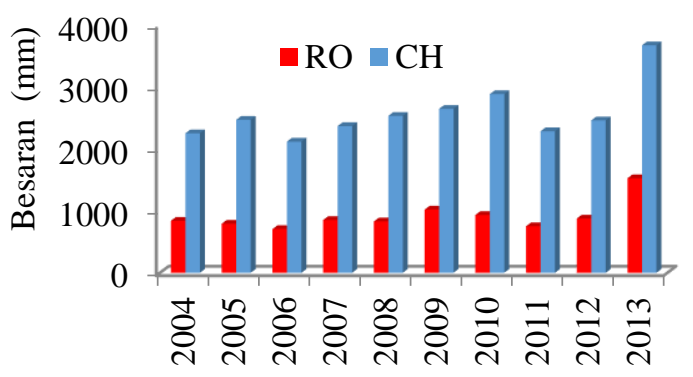

\section{Gambar 4. Distribusi runoff tahunan yang terjadi dari tahun 2004-2013}

\section{Kalibrasi sensor kadar air tanah}

Kalibrasi sensor dilakukan sebelum sensor tersebut digunakan di lapangan. Penentuan kadar air aktual dilakukan menggunakan metode gravimetri agar diperoleh nilai kadar air aktual yang lebih akurat. Pada penelitian ini, digunakan ring sample berdiameter $4,98 \mathrm{~cm}$ dan tinggi $5,2 \mathrm{~cm}$, sehingga volume sampel tanah yang bisa ditampung sebesar $101,33 \mathrm{~cm}^{3}$. Pengeringan tanah menggunakan oven dilakukan selama 24 jam pada suhu $100^{\circ} \mathrm{C}$ di Laboratorium Mekanika Tanah, Departemen Teknik Sipil dan Lingkungan, Institut Pertanian Bogor.

Data hasil pengukuran sensor dan kadar air aktual dibandingkan dan diplot pada grafik. Gambar 5 (a) dan Gambar 5 (b) berturut-turut menunjukkan grafik kalibrasi sensor 5TE dan EC-5. Dari gambar tersebut, terlihat bahwa sensor EC-5 mempunyai nilai korelasi $\mathrm{R}^{2}(0,92)$ lebih besar dibandingkan dengan sensor 5TE $(0,82)$. Hal ini disebabkan sensor EC-5 merupakan sensor yang keluarannya hanya berupa kadar air tanah, sedangkan sensor 5TE selain mengukur kadar air tanah juga mengukur suhu dan konduktifitas listrik tanah. Oleh karena itu, data kadar air tanah hasil pengukuran yang akan divalidasi merupakan data kadar air tanah hasil pengukuran sensor EC-5.

\section{Pengembangan bangunan resapan}

Pada penelitian ini, sistem penampungan dan peresapan air hujan yang dibuat adalah rorak yang disertai saluran pengumpul. Beberapa penelitian sudah dilakukan dan dibeberapa negara (Yeasmin \& Rahman 2013) menyebutkan bahwa konservasi air memanfaatkan air hujan sangat efektif dan efisien baik di musim hujan maupun di musim kemarau.

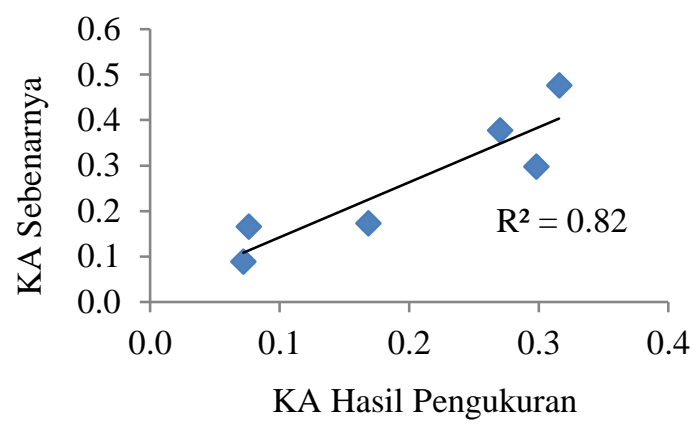

(a)

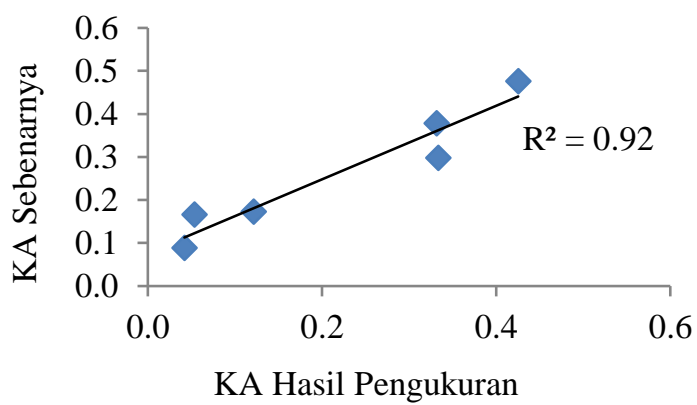

(b)

Gambar 5. Validasi kadar air tanah pengukuran dengan kadar air tanah aktual untuk sensor 5TE (atas) dan EC-5 (bawah)

Dimensi dan jumlah rorak dibuat berdasarkan potensi limpasan permukaan yang terjadi di lapangan. Faktor-faktor yang perlu diperhatikan dalam pembuatan rorak dan saluran pengumpul antara lain nilai koefisien rasional $C$, intensitas hujan maksimum (I), luas lahan berpotensi runoff (A) dan laju infiltrasi lahan. Penentuan nilai koefisien rasional $C$ dihitung menggunakan sistem komposit. Lokasi penelitian memiliki lima jenis tutupan lahan yang berbeda dengan luas lahan yang berbeda pula. Dengan sistem komposit, nilai $C$ yang diperoleh lebih akurat dan representatif. Penentuan nilai $C$ di lokasi penelitian berdasarkan jenis dan luas tutupan lahan disajikan pada Tabel 1. 
Tabel 1. Penentuan nilai koefisien rasional $\mathrm{C}$ di lokasi penelitian

\begin{tabular}{clcccc}
\hline No & \multicolumn{1}{c}{ Jenis tutupan lahan } & Nilai cn & Luas lahan $\left(\mathbf{m}^{2}\right)$ & Persentase & Cn*\% \\
\hline 1 & Pepohonan diselingi semak belukar & 86 & 2739 & $32,33 \%$ & 28 \\
2 & Semak belukar & 84 & 1080 & $12,74 \%$ & 11 \\
3 & Lahan ber-paving block (masjid, madrasah) & 98 & 3035 & $35,82 \%$ & 35 \\
4 & Lahan terbuka & 89 & 964 & $11,38 \%$ & 10 \\
5 & Jalan setapak (tanah yang dipadatkan) & 89 & 654 & $7,72 \%$ & 7 \\
\hline$\quad$ Total & 446 & 8472 & $100 \%$ & 91 \\
\hline \multicolumn{2}{c}{ Nilai CN yang digunakan : } & $\mathbf{9 1}$ & & & \\
\hline
\end{tabular}

Tabel 1 menggambarkan kondisi lokasi penelitian di beberapa titik mampu menekan limpasan permukaan, sedangkan beberapa titik lainnya tidak mampu. Tutupan lahan penyumbang limpasan permukaan terbesar yaitu lahan yang tertutup paving block dan jalan setapak. Desain rorak dan saluran peresapan menggunakan curah hujan rencana $\left(R_{24}\right)$ periode ulang 5 tahun dengan distribusi Gumbel. Distribusi Gumbel merupakan distribusi yang representatif dan mampu mewakili distribusi curah hujan di Indonesia. Beberapa penelitian menggunakan distribusi Gumbel dalam penentuan curah hujan rencana di Indonesia dengan nilai $R_{24}$ sebesar $111,08 \mathrm{~mm} /$ hari.

Pada perencanaan desain saluran, digunakan durasi hujan $\left(t_{c}\right)$ sebesar 2 jam sehingga diperoleh nilai intensitas hujan $(I)$ sebesar $24,26 \mathrm{~mm} / \mathrm{jam}$. Durasi hujan 2 jam dipilih karena pada durasi hujan tersebut, aliran permukaan berada pada kondisi maksimum. Susilowati dan Kusumastuti (2010) dalam penelitiannya menyebutkan bahwa rata-rata durasi hujan di Indonesia sebesar 4 jam dengan curah hujan $90 \%$ terkonsentrasi dari jumlah hujan selama 24 jam. Namun, untuk keperluan desain sistem penampungan dan peresapan air hujan dipilih kemungkinan durasi hujan 2 jam untuk memperkecil resiko terlampauinya peluang terjadi banjir.

Untuk pendugaan limpasan permukaan, dengan menggunakan Persamaan (4) diperoleh nilai limpasan permukaan sebesar $0,00064 \mathrm{~m}^{3} / \mathrm{dt}$. Angka tersebut sudah dikurangi laju infiltrasi di lapang sebesar 2,22 $\mathrm{mm} / \mathrm{jam}$ atau $0,00018 \mathrm{~m}^{3} / \mathrm{dt}$. Untuk menghilangkan runoff sebesar $0,00064 \mathrm{~m}^{3} / \mathrm{dt}$ atau 7,7 mm di lokasi penelitian, dibangun 2 buah rorak utama berdimensi 100 x 100 x $40 \mathrm{~cm}$. Kedua buah rorak utama ini diletakkan di hulu lokasi penelitian. Kemudian, untuk menopang kinerja rorak utama, diperlukan rorak tambahan sebanyak 10 buah dengan dimensi 60 x 60 x $40 \mathrm{~cm}$. Rancangan rorak dan saluran pengumpul serta realisasi di lapangan disajikan pada Gambar 6 dan Gambar 7.

Rorak dan saluran pengumpul diletakkan secara menyebar di lokasi penelitian dan tidak tergantung oleh jarak antar rorak. Rorak utama diletakkan di bagian hulu sedangkan rorak tambahan diletakkan di bagian tengah sampai hilir. Seluruh badan rorak terbuat dari tanah agar dapat meresapkan air ke dalam tanah. Pada dasar rorak, boleh ditambahkan serasah agar dapat menambah daya serap tanah. Untuk saluran pengumpul, dibuat searah kontur dan menghubungkan rorak satu dengan rorak lainnya. Pemetaan rorak dan saluran pengumpul disajikan pada Gambar 8.

\section{Model analisis kesetimbangan air dengan runoff (sebelum ZROS diterapkan)}

Simulasi ini merupakan simulasi kesetimbangan air pada ZROS sebelum dibangun sistem penampungan dan peresapan air hujan. Artinya, pada kondisi ini curah hujan yang jatuh tidak dapat dimanfaatkan dan terbuang dalam bentuk runoff. Nilai kadar air tanah harian selama penelitian pada kedalaman 0-25 cm hasil simulasi disajikan dalam bentuk grafik pada Gambar 9 (a).

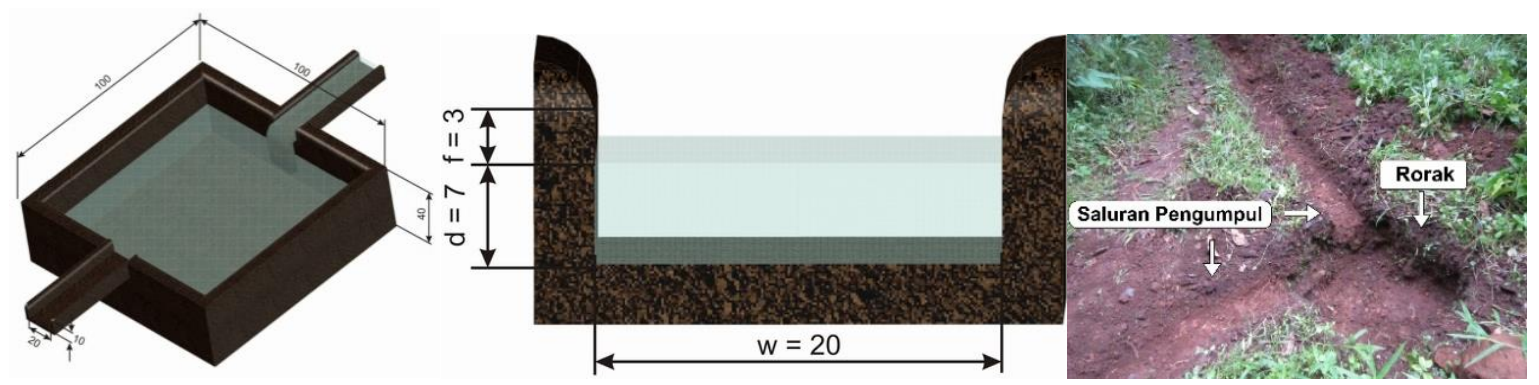

Gambar 6. Desain bangunan resapan tiga dimensi dan realisasi di lapangan 

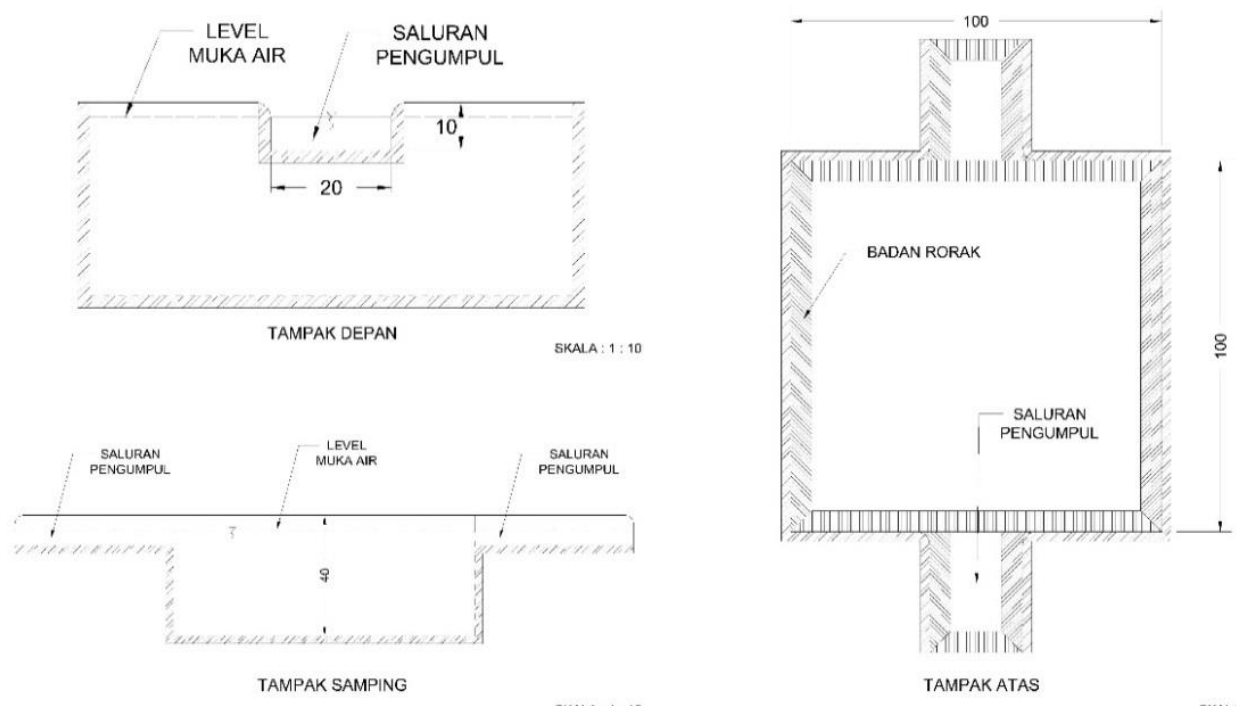

SKALA: $1: 16$

TAMPAK ATAS

SKALA: $1: 12$

Gambar 7. Desain bangunan resapan (rorak dan saluran pengumpul)

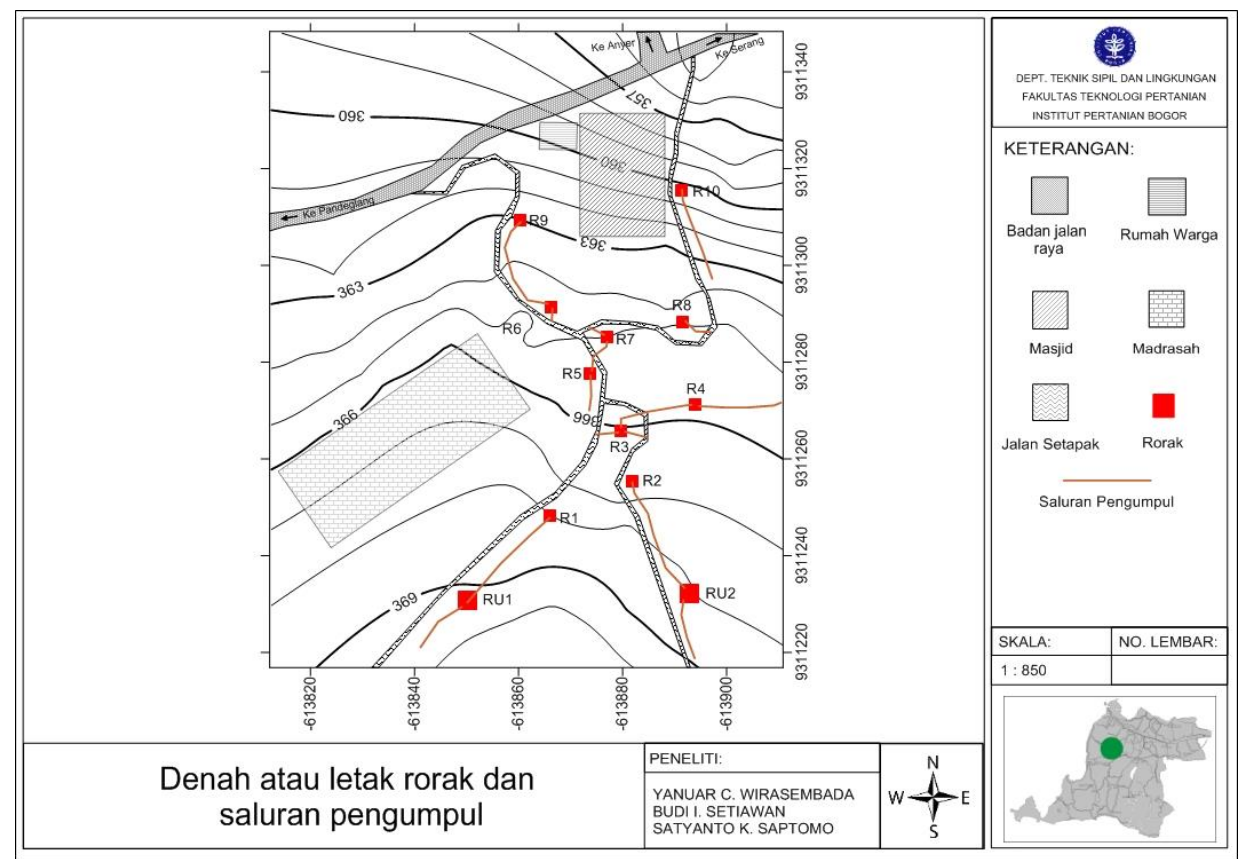

Gambar 8. Layout rorak dan saluran pengumpul di lokasi penelitian

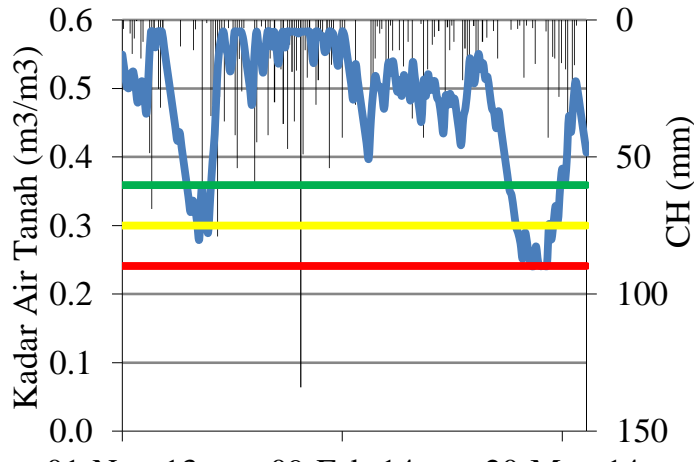

01-Nov-13 09-Feb-14 20-May-14

$\mathrm{CH} \longrightarrow \mathrm{KA} \longrightarrow \mathrm{WP}=\mathrm{FC}-\mathrm{SC}$

(a)

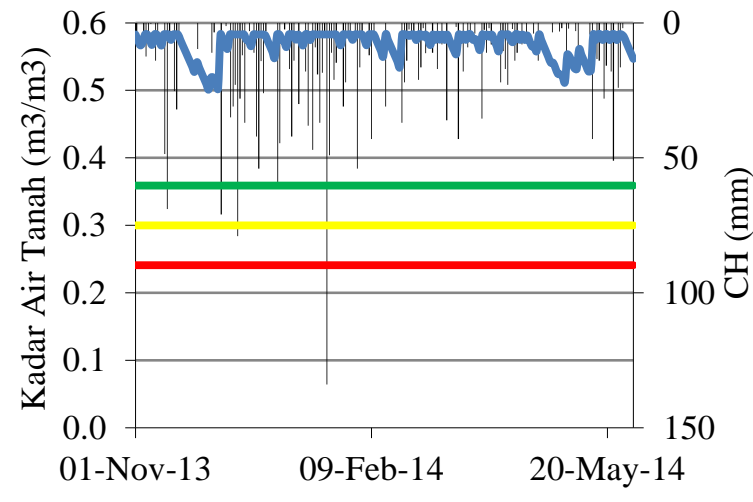

$\mathrm{CH} \longrightarrow \mathrm{KA} \longrightarrow \mathrm{WP} \longrightarrow \mathrm{FC} \longrightarrow \mathrm{SC}$

(b)

Gambar 9. Hasil simulasi kadar air tanah selama penelitian (a) tanpa ZROS dan (b) dengan ZROS 
Gambar tersebut menunjukkan bahwa nilai kadar air tanah hasil simulasi secara grafis menunjukkan pola yang serupa dengan pola curah hujan. Pada periode tidak terjadi hujan, kadar air tanah menurun secara bertahap. Demikian pula, pada saat terjadi hujan maka kadar air tanah kembali meningkat. Melalui simulasi ini, kadar air tanah dapat dikontrol dan diketahui secara harian. Prediksi kadar air tanah yang mencapai batas titik layu permanen juga dapat diketahui. Simulasi ini sangat bermanfaat dan cocok untuk mengetahui perubahan kadar air tanah khususnya dibidang pertanian. Melalui simulasi ini pula, tindakan preventif dapat dilakukan agar kondisi tanah tetap menyediakan kadar air tanah yang cukup.

\section{Model analisis kesetimbangan air tanpa runoff (setelah ZROS diterapkan)}

Simulasi ini merupakan simulasi kesetimbangan air pada ZROS setelah dibangun sistem penampungan dan peresapan air hujan. Artinya, pada kondisi ini, curah hujan yang jatuh di lapangan diasumsikan seluruhnya dapat diresapkan sehingga runoff menjadi tidak ada atau nol. Nilai kadar air tanah harian pada kedalaman 0-25 cm hasil simulasi disajikan dalam bentuk grafik pada Gambar 9 (b).

Gambar tersebut menunjukkan bahwa nilai kadar air tanah hasil pengukuran dan model secara grafis menunjukkan pola curah hujan. Perbedaan yang terlihat yaitu pada simulasi tanpa aliran permukaan, kadar air tanah berada pada level yang cukup. Hal tersebut terlihat dari kurva kadar air tanah hampir seluruhnya berada di atas kapasitas lapang. Kondisi stress hanya terjadi beberapa hari pada awal Desember 2013 dan pada awal Mei 2014 tetapi kondisi ini tidak sampai menyentuh batas titik layu permanen. Hal ini disebabkan runoff yang terjadi di lokasi penelitian dapat diresapkan ke dalam tanah sehingga dapat menambah cadangan air tanah pada musim kemarau.

Pada tanggal 21 Januari 2014 curah hujan yang terjadi sebesar $134 \mathrm{~mm} /$ hari sedangkan curah hujan rencana sebesar $111 \mathrm{~mm} /$ hari. Pada kondisi ini, terjadi kondisi di mana curah hujan melampaui curah hujan rencana. Kondisi ini mengakibatkan rorak dan saluran pengumpul tidak mampu menampung dan meresapkan air hujan sehingga terjadi banjir. Pada kondisi ini, terjadi runoff sebesar 2,5 mm atau setara dengan $750 \mathrm{~m}^{3}$ air yang tidak mampu diresapkan oleh rorak.

\section{Efektifitas ZROS dan validasi model}

Efektifitas zero runoff system (rorak dan saluran pengumpul) dalam mengendalikan aliran permukaan dapat dilihat dari nilai kadar air tanah di zona perakaran tanaman dibandingkan dengan tanpa zero runoff system. Hasil simulasi menunjukkan bahwa nilai kadar air tanah tanpa ZROS maupun dengan ZROS relatif tinggi, bahkan diatas nilai kapasitas lapang (Gambar 10).

Untuk kadar air tanah tanpa ZROS, kadar air tanah berkisar antara $0.341-0.557 \mathrm{~m}^{3} / \mathrm{m}^{3}$ dengan rata-rata $0.476 \mathrm{~m}^{3} / \mathrm{m}^{3}$. Sedangkan untuk kadar air tanah dengan ZROS, kadar air tanah berkisar antara $0.363-0.557 \mathrm{~m}^{3} / \mathrm{m}^{3}$. Kondisi tersebut terjadi karena selama penelitian curah hujan relatif tinggi dan tidak terjadi kemarau yang berkepanjangan. Namun, hasil simulasi dari tahun 2004 sampai 2013 menunjukkan bahwa kadar air tanah dengan ZROS relatif lebih tinggi dibandingkan dengan tanpa ZROS.

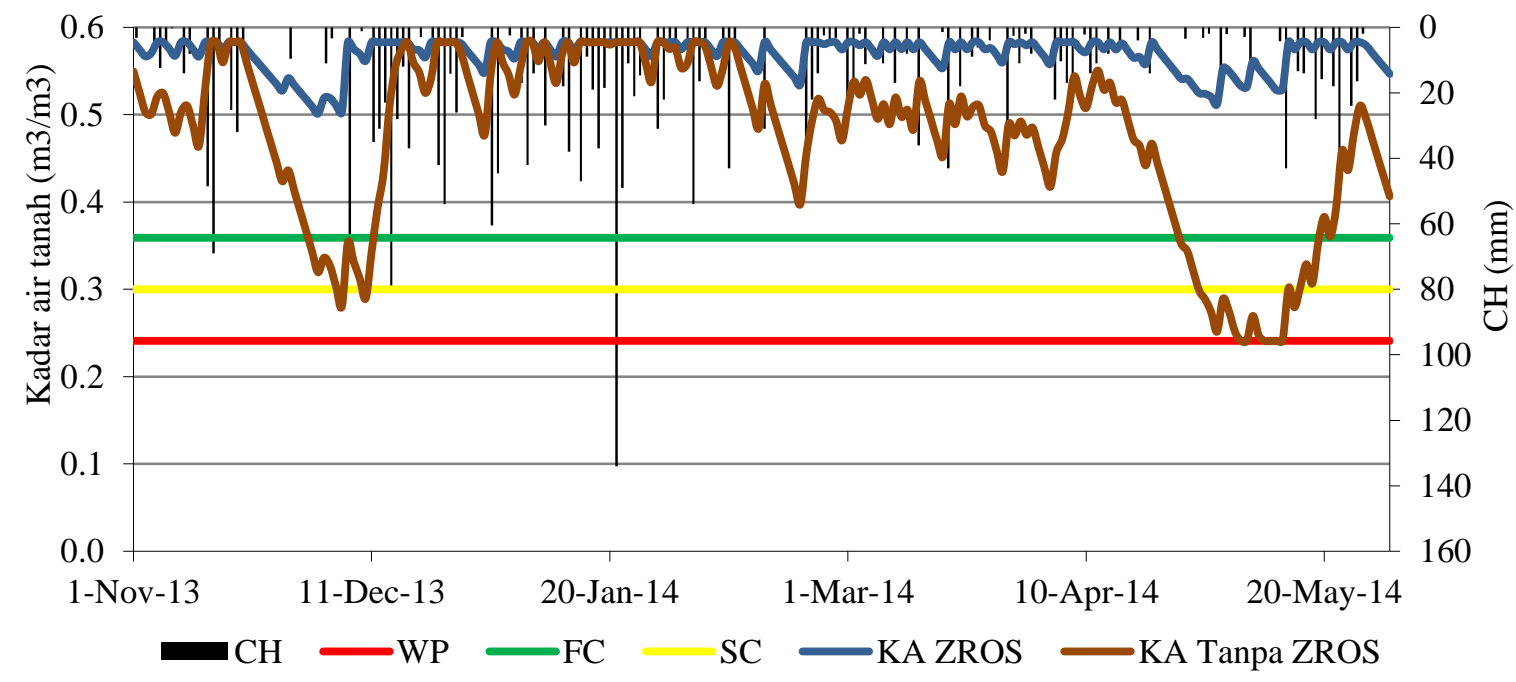

Gambar 10. Kadar air tanah dengan dan tanpa ZROS selama penelitian 


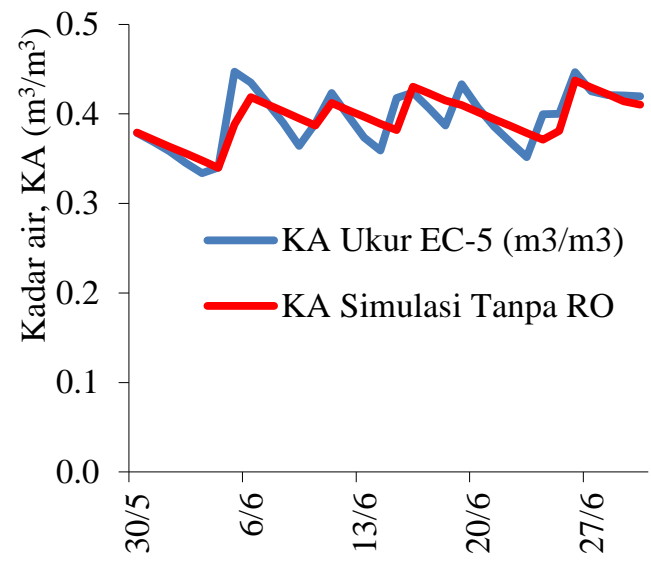

(a)

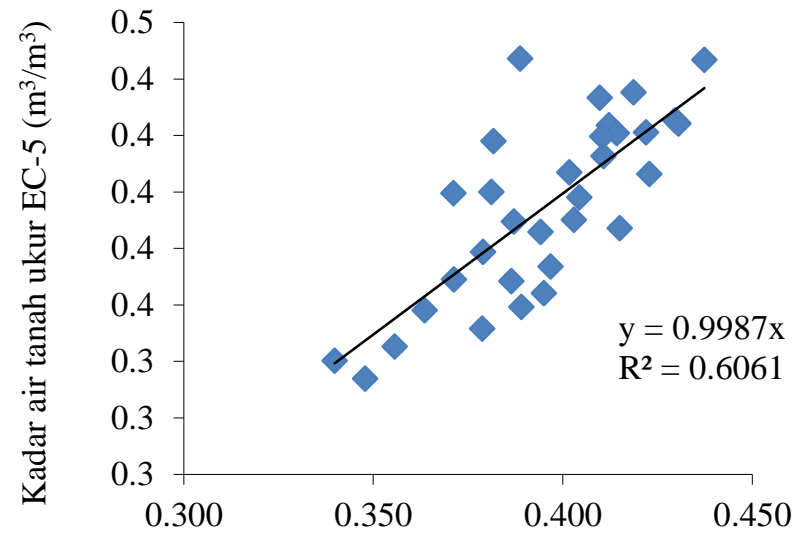

Kadar air tanah simulasi tanpa RO $\left(\mathrm{m}^{3} / \mathrm{m}^{3}\right)$

(b)

Gambar 11. (a) Kurva perbandingan kadar air tanah hasil pengukuran dan hasil simulasi, (b) Validasi kadar air tanah hasil pengukuran dan hasil simulasi

Hasil simulasi menunjukkan bahwa dengan ZROS, nilai kadar air tanah di lokasi penelitian berada pada kondisi yang cukup untuk memenuhi kebutuhan air tanaman. Walaupun lokasi penelitian bukan merupakan lahan pertanian khusus, tanaman yang ditanam di areal tersebut antara lain pisang, melinjo, menteng dan durian tetap dapat bertahan hidup dan berproduksi sepanjang tahun. Abdurachman et. al (2006) mengungkapkan bahwa tanaman akan stress pada kondisi kadar air tanah < $50 \%$ dari kapasitas lapang sehingga menurunkan produksi.

Validasi model dilakukan dengan cara membandingkan kadar air tanah hasil pengukuran dengan kadar air tanah hasil simulasi. Pengukuran kadar air tanah dilakukan selama satu bulan (30 Mei sampai 30 Juni 2014). Perbandingan kedua data tersebut disajikan pada Gambar 11 (a). Validasi ini menghasilkan nilai tingkat kepercayaan $\left(\mathrm{R}^{2}\right)$ sebesar 0.606 [Gambar 11 (b)]. Angka tersebut cukup tinggi karena kalibrasi dilakukan hanya dalam periode satu bulan. Sebaiknya, untuk mencapai nilai $\mathrm{R}^{2}$ yang optimal, pengukuran kadar air tanah dilakukan dengan jangka waktu yang lebih lama.

\section{Kesimpulan}

Konsep Zero Runoff System (ZROS) telah diujicobakan di perkebunan di DAS Cidanau, Banten. Hasil uji coba menunjukkan bahwa ZROS mampu menyerap dan mengurangi limpasan permukaan. Hal ini terlihat dari meningkatnya kadar air tanah di lokasi penelitian setelah diterapkan ZROS. Rata-rata kadar air tanah setelah diterapkan ZROS sebesar $0.569 \mathrm{~m}^{3} / \mathrm{m}^{3}$ sedangkan sebelum ZROS sebesar $0.476 \mathrm{~m}^{3} / \mathrm{m}^{3}$.
Bangunan resapan yang dibuat berjumlah 12 rorak, dengan dua rorak berdimensi panjang, lebar dan tinggi berturut-turut sebesar $100 \times 100 \times 40 \mathrm{~cm}$ dan 10 rorak berdimensi $60 \times 60 \times 40 \mathrm{~cm}$. Estimasi Runoff yang terjadi di lokasi penelitian sebesar $35,26 \%$ dari curah hujan tahunan. Model analisis kesetimbangan air dengan dan tanpa ZROS menunjukkan bahwa kinerja model relatif valid dalam mensimulasikan kadar air tanah harian di lokasi penelitian. Hal ini ditunjukkan dari nilai $\mathrm{R}^{2}$ yang cukup tinggi, yaitu sebesar 0,606. Angka tersebut diperoleh dari validasi selama satu bulan pengukuran. Angka $\mathrm{R}^{2}$ dapat lebih tinggi apabila pengukuran dilakukan dengan periode waktu yang lebih lama.

\section{Daftar Pustaka}

Abdurachman, A., Haryati, U., Juarsah, I. (2006). Penetapan Kadar Air Tanah dengan Metode Gravimetri. Jakarta (ID): Balai Besar Litbang Sumberdaya Lahan Pertanian.

Afolayan, S. O., Makinde, A. A., Shuaib, M., Idris, B. A., Yaduma, J. J., \& Yau, M. G. (2012). Rainfall Harvesting, a Sustainable Water Management Alternative for Food Security in Nigeria. Science Journal of Agricultural Research and Management, (136):1-8.

Bowo, C., Hasan, M., \& Marhaenanto, B. (2009). Penentuan Kurva Retensi Air Tanah Laboratorium Dengan Sensor Resistensi dan Kapasitansi. Jurnal Tanah Tropika (Journal of Tropical Soils), 14(1), 57-64.

Chow, V.T., Maidment DR, Mays LW. (1988). Applied Hydrology. New York:McGraw-Hill. 
Kumar, P.S., Rishi, H. (2013). Simulation of rainfall runoff using SCS and RRL (Case Study Tadepalli Mandal). International Journal of Engineering Research and General Science. 1(1),1-11.

Kumar, R., Thaman, S., Agrawal, G., Poonam, S.. (2011). Rain Water Harvesting and Ground Water Recharging in North Western Himalayan Region for Sustainable Agricultural Productivity. Journal of Environmental Research and Technology, 1(4), 539-544.

Luxon, N., Pius, C. (2013). Validation of The Rainfall-Runoff SCS-CN Model in a Catchment with Limited Measured Data in Zimbabwe. International Journal of Water Resources and Environmental Engineering, 5(6), 295-303.

Oni, S.I., Ege, E., Asenime, C., Oke, S.A. (2008). Rainwater Harvesting Potential for Domestic Water Supply in Edo State. Journal of Management \& Social Sciences, 2(2), 87-98.

Otti, V.I., Ezenwaji, E.E. (2013). Enhancing community-driven initiative in Rainwater Harvesting in Nigeria. International Journal of Engineering and Technology, 3(1):73-79

Pereira, L.S., Allen, R.G. (1999). Irrigation and Drainage. In: van Lier HN, Pereira LS, Steiner FR. (Editors). CIGR Handbook of Agricultural Engineering Vol. I Land \& Water Engineering. American Society of Agricultural Engineering. Chapter 5.

Reshma, T., Kumar, P.S., Babu, R.K., Kumar, K.S. (2010). Simulation of Runoff in Watershed Using
SCS-CN and Muskingum-Cunge Methods Using Remote Sensing and Geographical Information Systems. International Journal of Advanced Science and Technology, 25(31), 3-42.

Steenhuis, T.S., Winchell, M., Rossing, J., Zollweg, J., Walter, M.F. (1995). SCS Runoff Equation Revisited for Variable-Source Runoff Areas. Journal of Irrigation and Drainage Engineering, 234-238.

Surdianto, Y. (2012). Analisis Kecukupan Air di Kebun Belimbing Manis. Disertasi. Institut Pertanian Bogor, Bogor.

Susilowati, Kusumastuti, D.I. (2010). Analisa karakteristik curah hujan dan kurva Intensitas Durasi Frekuensi (IDF) di Provinsi Lampung. Jurnal Rekayasa, 14(1): 47-52.

Tejaswini, N.B., Shetty, A., Hegde, V.S. (2011). Land use scenario analysis and prediction of runoff using SCS-CN Method: A case study from the Gudgudi Tank, Haveri District, Karnataka, India. International Journal of Earth Sciences and Engineering, 4(5):845-853.

[USDA] United States Departement of Agriculture. 1986. Urban Hydrology for Small Watersheds. Department of Agriculture, United States.

Yeasmin, S., Rahman, K.F. (2013). Potential of rainwater harvesting in Dhaka CityL Am Empirical Study. ASA University Review, 7(1): 143-150. 